\title{
A Hand-Portable Single Nozzle Rainfall Simulator Designed for Use on Steep Slopes
}

\author{
BRADFORD P. WILCOX, M. KARL WOOD, JOHN T. TROMBLE, AND TIMOTHY J. WARD
}

\section{Abstract}

The objective of this study was to develop a small plot $\left(1 \mathrm{~m}^{2}\right)$ rainfall simulator operational on steep terrain in the Guadalupe Mountains of New Mexico. The simulator developed is handportable and consists of a spray head assembly mounted on 3 adjustable legs. A 946-liter tank equipped with a gasoline powered pump was connected to the spray head assembly via rubber garden hoses. On steep slopes gravity provided sufficient pressure to operate the simulator. Site selection was limited to areas where the water tank could be located in a suitable upslope position. The simulator has been used for 2 years on 170 plots and has proved durable. Advantages of this device are the low cost of construction and operation, and the flexibility in plot-site selection it provides. The principal disadvantages are associated with the single stationary nozzle, such as uneven application of water at small drop sizes and low kinetic energies.

An ideal rainfall simulator has yet to be developed. Those that most closely reproduce rainfall patterns and intensity are expensive and require large expenditures of manpower for setup and operation (Foster et al. 1979). However, rainfall simulators, even though imperfect, are essential tools for investigating hydrologic processes on arid and semiarid rangeland where rainfall events are sporadic. Simulator experiments can be used to estimate infiltration, interrill erosion runoff rates, and chemical water quality for given storm events. Impacts of range management practices (grazing strategy, brush control, reseeding) on the watershed can also be evaluated using rainfall simulators. Rainfall simulators can be used to collect data in a relatively short period, rather than the 10 to 20 years needed to collect sufficient information from natural rainfall events. Rainfall simulators also provide maximum control over plot conditions and rainfall characteristics.

Rainfall simulators in common use by range watershed scientists are the mobile drop-forming (Blackburn et al. 1974), Rocky Mountain infiltrometer (Dortignac 1951) and versions of the Purdue type (Bertrand and Parr 1961). All the above provide mobility, but use of each is restricted to relatively flat terrain. Hand-portable infiltrometers have been developed (Adams et al. 1957, McQueen 1963, Selby 1970, Munn and Huntington 1976, Malekuti and Gifford 1978) and are more suitable for rugged terrain. Munn and Huntington (1976) report the Tahoe Basin infiltrometer to be functional on slopes to $60 \%$. Hand-portable infiltrometers, however, have not been widely used, perhaps because many are bulky, heavy, require pumps or motors, or have a limited water supply. This paper presents the construction, operation, rainfall characteristics, and limitations of a hand-portable small rainfall simulator developed for use on steep slopes in the Guadalupe Mountains of New Mexico.

\section{Materials and Methods}

The simulator employs a single stationary nozzle. Various full cone nozzles can be used depending on the desired drop size and velocity, area to be covered, and application rate (Bubenzer 1979).

Authors are instructor, Department of Earth Resources, Colorado State University, Ft. Collins, 80523; associate professor, Department of Animal and Range Sciences, New Mexico State University, Las Cruces 88003; range hydrologist, Jornada Experimental Range, U.S. Department of Agriculture, Agriculture Research Service, Las Cruces, New Mexico 88003; and associate professor, Department of Civil Engineering, New Mexico State University, Las Cruces 88003 . This article is published as Journal Article No. 1146, New Mexico State University Agricultural Experiment Station.

Manuscript accepted 4 November 1986.
The nozzle used on this simulator is a $1 / 4 \mathrm{G} 10$ full jet manufactured by Spraying Systems Company, Engineers and Manufacturers in Wheaton, Illinois. The simulator consists of a spray head assembly and three adjustable support legs (Fig. 1). A listing and cost of all

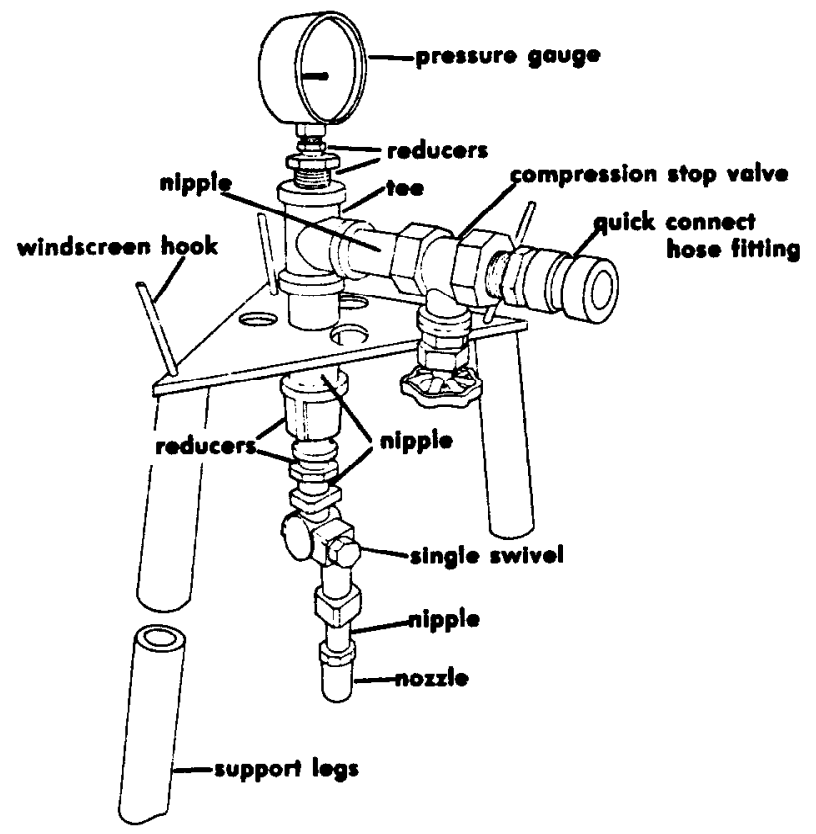

Fig. 1. Schematic of spray-head assembly.

parts is shown in Table 1. The frame for the spray head assembly is made up of a $0.635-\mathrm{cm}$ triangular steel plate with $2.54-\mathrm{cm}$ diameter steel pipes welded at an angle on each corner. A 1.9-cm steel nipple is inserted through a hole cut in the middle of the plate and welded in place. Pressure is monitored with a low pressure steam gauge and regulated with a compression stop valve. The spray head assembly was connected to a 946 -liter water tank via $1.9-\mathrm{cm}$ garden hose. The 3 support legs are made of $1.27-\mathrm{cm}$ conduit pipe inserted in 1.9-cm conduit, both of which are $150 \mathrm{~cm}$ long. The support legs are inserted into the $2.54-\mathrm{cm}$ diameter steel pipe on the spray head assembly. Adjustment is accomplished by moving the smaller pipe until desired length is achieved. Tightening a bolt through a nut welded on the $1.9-\mathrm{cm}$ conduit prevents further movement. Similarly constructed legs can be hooked through holes cut in the triangular plate to serve as wind screen supports (Fig. 1). A light weight plastic wind screen wraps around the legs (Fig. 2).

Intensity measurements at 6 pressures and 3 measurement heights were made by raining on a meter square steel tray designed to collect and deliver runoff. At each combination of height and pressure three 2-minute readings were taken.

Drop sizes were determined by the flour pan method outlined by Laws and Parsons (1943). A meter survey tray was covered with about $1.5 \mathrm{~cm}$ of sieved flour and rained on for less than a second at 6 operating pressures. The nozzle was 1.98 meters from the tray. Two replications were made at each pressure except at $68.9 \mathrm{kPa}$. The flour was air dried for 24 hours before the pellets were separated into size classes by sieving and weighing. Total weight of the pellets in each size class was determined for 9 equal size quad- 


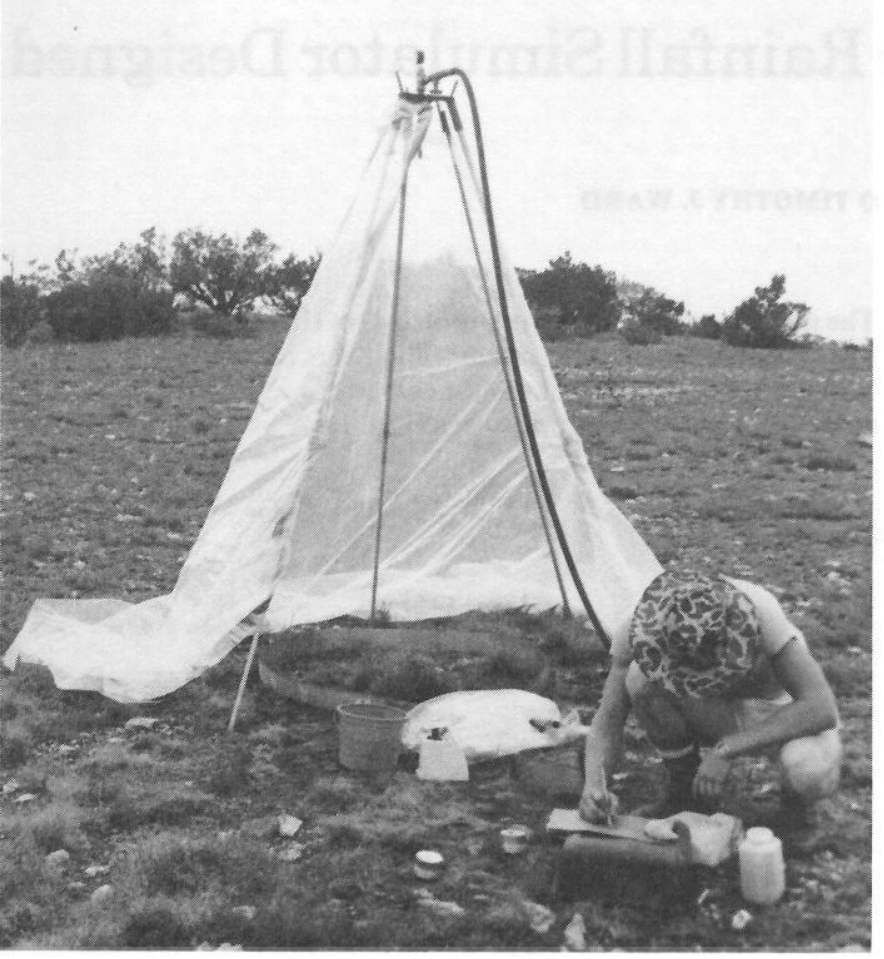

Fig. 2. Light weight plastic sheets wrapped around the frame serve as wind screens and provide some anchorage.

rats $\left(0.11 \mathrm{~m}^{2}\right)$ within the tray. Cumulative frequency curves were constructed for the center quadrat, the combined outside quadrats, and the entire tray for each replication, from which drop size distributions were determined.

\section{Results and Discussion}

Intensity measurement at various operating pressures and instrument heights are presented in Table 2 . At $152 \mathrm{~cm}$ intensity is greater than at the other 2 heights for the same pressure. Drop sizes are presented in Table 3. Drop sizes generally decrease with an increase in nozzle pressure. However, D84 and D50 at $137.9 \mathrm{kPa}$ is slightly higher than D84 and D50 at $103.4 \mathrm{kPa}$. The difference can probably be explained as experimental error. D84, D50 and D16 are the drop sizes at which 84,50 , and $16 \%$ of the drops are finer, respectively.

This simulator has been used for 2 summers in the Guadalupe Mountains of southwestern New Mexico during which time 170 small plots have been run. It was well suited for the steep slopes for which it was designed (Fig. 3). It was used on slopes over 70\%. On these types of slopes the watertank trailer was parked in a suitable upslope position and connected to the simulator by garden hose.
Table 1. Parts and price list for the rainfall simulator.

\begin{tabular}{lccr}
\hline \hline & & $\begin{array}{c}\text { Approximate } \\
\text { Price/ } \\
\text { unit }(\$)\end{array}$ & $\begin{array}{r}\text { Total } \\
\text { price }\end{array}$ \\
\hline $1.905 \mathrm{~cm}$ conduit & No & 2.50 & 12.50 \\
$1.27 \mathrm{~cm}$ conduit & 5 & 1.75 & 8.75 \\
Steam gauge & 1 & 6.50 & 6.50 \\
$2.54 \mathrm{~cm}$ steel pipe & 1 & 1.50 & 1.50 \\
$.635 \mathrm{~cm}$ steel plate & 1 & 3.00 & 3.00 \\
$1.905 \mathrm{~cm}$ tee & 1 & 1.29 & 1.29 \\
$1.905 \mathrm{~cm}$ nipple & 2 & .49 & .98 \\
$1.905 \mathrm{~cm}$ compression stop valve & 1 & 3.99 & 3.99 \\
pipe-hose converter & 1 & 1.74 & 1.74 \\
quick connect hose fitting & 1 & 5.19 & 5.19 \\
wingbolt and nut & 5 & .37 & 1.85 \\
$.635 \mathrm{~cm}-.3175 \mathrm{~cm}$ reducer & 1 & .59 & .59 \\
$1.905 \mathrm{~cm}-.635 \mathrm{~cm}$ reducer & 1 & .69 & .69 \\
$1.905 \mathrm{~cm}-1.27 \mathrm{~cm}$ reducer & 1 & 1.09 & 1.09 \\
$1.27 \mathrm{~cm}-.92525 \mathrm{~cm}$ reducer & 1 & .59 & .59 \\
$9525 \mathrm{~cm}$ steel rod & 1 & .50 & .50 \\
$1 / 4 \mathrm{G} 10$ full jet nozzle & 1 & 4.34 & 4.34 \\
single swivel $5000-1$ & 1 & 4.78 & 4.78 \\
\cline { 2 - 4 } Total Price & & & 59.87 \\
\hline
\end{tabular}

On steep slopes gravity provides sufficient pressure to operate the simulator. Distance of the plots from the water trailer is limited by the length of garden hose and the distance one is willing to carry equipment (plot frames, simulator, water bottles, other data collection equipment). The simulator was set up in a few minutes and it was easily moved from plot to plot. The most laborious task was moving equipment up and down the slopes. On level terrain water was delivered to the nozzle with a gas powered pump on the supply line. One could also pump uphill if necessary.

There are some problems with the single stationary nozzles (Mutchler and Hermsmeier 1965). First, water is unevenly applied over the plot. Elkins (1983) used the same nozzles on a Purdue rainfall simulator and reported that when average intensity was $12.3 \mathrm{~cm} / \mathrm{hr}$, the center of the plot $\left(1 \mathrm{~m}^{2}\right)$ was receiving over 23 $\mathrm{cm} / \mathrm{hr}$ while the intensity at the perimeter of the plot averaged only $6.6 \mathrm{~cm} / \mathrm{hr}$. Nozzle height in his experiment was $275 \mathrm{~cm}$. This problem could be partially alleviated by using smaller plots. Second, drop sizes produced by the 1/4G10 full jet are smaller than natural rainfall at the same intensity. Laws and Parsons (1943) reported that average drop diameter for a $10 \mathrm{~cm} / \mathrm{hr}$ intensity natural rainfall event is about $2.8 \mathrm{~mm}$. Median drop size (D50) for $10 \mathrm{~cm} / \mathrm{hr}$ produced by this nozzle is $1.2 \mathrm{~mm}$. Because of the small size, kinetic energy of a simulated rainfall of $10 \mathrm{~cm} / \mathrm{hr}$ is only about $36 \%$ of that of a natural rainfall event of the same intensity. The above conclusion is based on Laws (1941) research on raindrop terminal velocity and Laws and Parsons (1943) measurements of a raindrop size and their relationship to intensity. Their work was done in the Washington, D.C., area. The above limitations are

Table 2. Mean intensity $(\mathrm{cm} / \mathrm{hr})$ and respective standard deviations $(\mathrm{cm} / \mathrm{hr})$ for different combinations of pressure and nozzle height.

\begin{tabular}{|c|c|c|c|c|c|c|}
\hline \multirow{3}{*}{$\begin{array}{c}\text { Pressure } \\
(\mathrm{kPa})\end{array}$} & \multicolumn{6}{|c|}{ Nozzle height $(\mathrm{cm})$} \\
\hline & \multicolumn{2}{|c|}{244} & \multicolumn{2}{|c|}{198} & \multicolumn{2}{|c|}{152} \\
\hline & I & SD & I & $\mathrm{SD}$ & I & $\mathrm{SD}$ \\
\hline 137.9 & 15.0 & 0.30 & 15.00 & 0.51 & 20.25 & 0 \\
\hline 103.4 & 12.9 & 0.15 & 13.00 & 0.18 & 17.10 & 0.18 \\
\hline 82.7 & 12.0 & 0 & 12.30 & 0.30 & 14.10 & 0.27 \\
\hline 69.0 & 11.61 & 0.45 & 11.01 & 0.15 & 12.09 & 0.18 \\
\hline 48.3 & 9.84 & 0.09 & 10.29 & 0.36 & 11.16 & 0.18 \\
\hline 34.5 & 8.76 & 0.24 & 8.79 & 0.18 & 9.51 & 0.42 \\
\hline 20.7 & 6.9 & 0.15 & 6.99 & 0.42 & 7.11 & 0.39 \\
\hline
\end{tabular}


Table 3. Drop diameters $(\mathrm{mm})$ for outside edge, center, and entire tray at different presures. Nozzle height was $200 \mathrm{~cm}$.

\begin{tabular}{|c|c|c|c|c|c|c|c|c|c|c|c|c|c|c|c|c|}
\hline & \multicolumn{16}{|c|}{ Pressure $(\mathrm{kPa})$} \\
\hline & \multirow{2}{*}{$\frac{137.9}{\bar{x}}$} & \multicolumn{3}{|c|}{103.4} & \multicolumn{3}{|c|}{69.0} & \multicolumn{3}{|c|}{48.3} & \multicolumn{3}{|c|}{34.5} & \multicolumn{3}{|c|}{20.7} \\
\hline & & $x_{0}$ & $\bar{x}$ & $\mathrm{x}_{\mathrm{c}}$ & $\bar{x}$ & $\bar{x}$ & $\mathrm{x}_{\mathrm{c}}$ & $\mathrm{x}_{\mathrm{o}}$ & $\bar{x}$ & $\mathrm{x}_{\mathrm{c}}$ & $\mathrm{x}_{\mathrm{o}}$ & $\bar{x}$ & $\mathrm{x}_{\mathrm{c}}$ & $\mathrm{x}_{\mathrm{o}}$ & $\bar{x}$ & $\mathrm{x}_{\mathrm{c}}$ \\
\hline D84 & 1.6 & 1.5 & 1.6 & 1.8 & 1.4 & 1.7 & 2.1 & 1.5 & 1.9 & 2.6 & 1.5 & 1.8 & 2.4 & 1.7 & 2.4 & 2.8 \\
\hline D50 & 1.1 & 1.0 & 1.0 & 1.1 & 1.0 & 1.1 & 1.4 & 1.0 & 1.2 & 1.5 & 1.1 & 1.2 & 1.5 & 1.2 & 1.5 & 2.0 \\
\hline D16 & 0.8 & 0.8 & 0.8 & 0.8 & 0.8 & 0.8 & 0.8 & 0.8 & 0.8 & 0.8 & 0.8 & 0.8 & 0.9 & 0.8 & 0.9 & 1.2 \\
\hline
\end{tabular}

$\bar{x}=$ total plot

$\mathrm{x}_{\mathrm{o}}=$ outside perimeter of plot

$\mathrm{x}_{\mathrm{c}}=$ center of plot

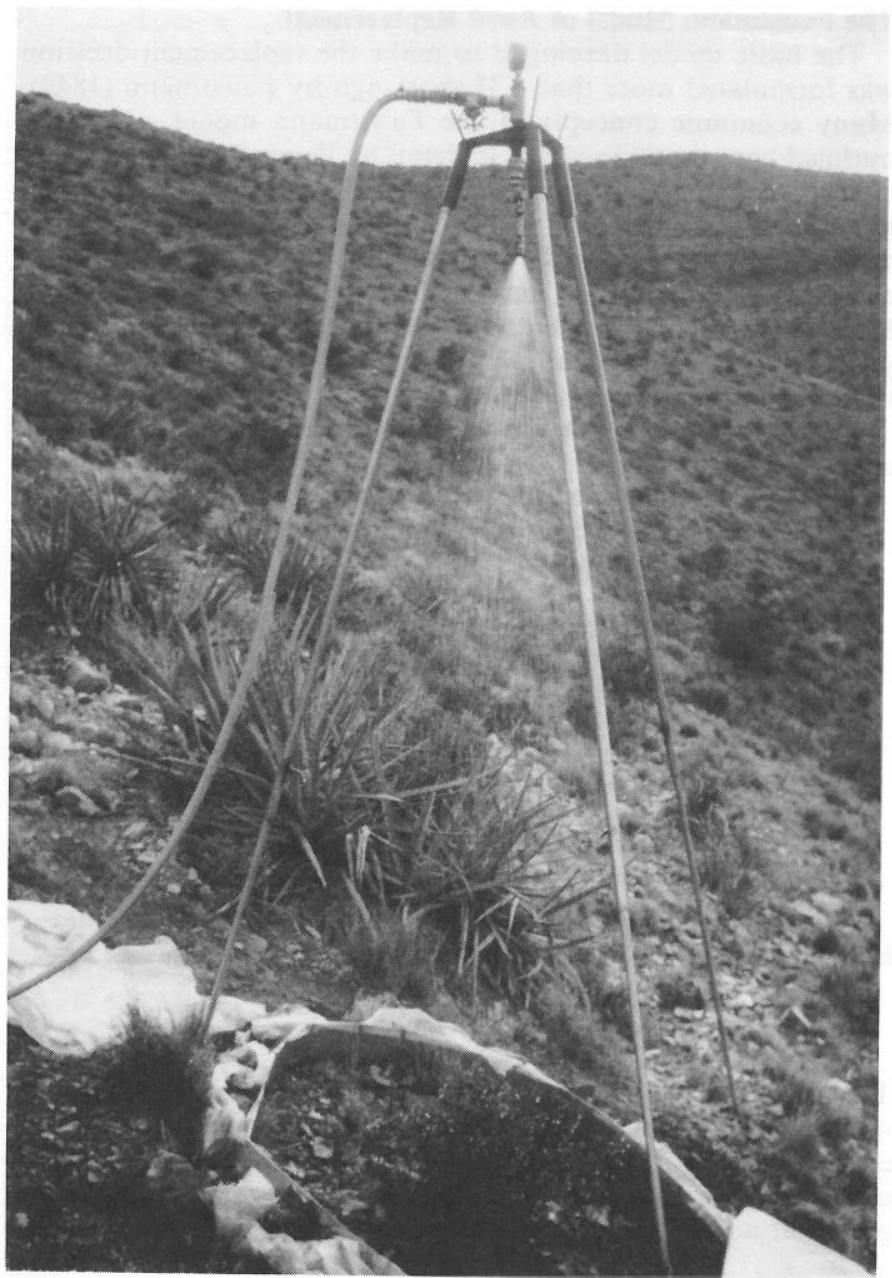

Fig. 3. The rainfall simulator is well suited for rugged terrain.

functions of the nozzle used. The delivery system can be used with any number of nozzles. Other nozzles may eliminate some of these problems.

There are several advantages with the delivery system of this device. First, it proved very usable on steep slopes. Second, the delivery system is light weight, very durable, and relatively inex- pensive. On level terrain it has some advantages over the more conventional type of rainfall simulators. The drop forming type (Blackburn 1974) and the Purdue type (Bertrand and Parr 1961) are designed for paired plots. This requirement restricts plot size selection. The portable simulator described here has no such requirement. Site disturbance because of vehicle travel is much less with this type of delivery system since the water trailer need only be parked and the simulator can be hand carried from plot to plot. If one is willing to accept the limitations of a single stationary nozzle, this type of rainfall simulator can provide valuable information, especially on steep slopes.

\section{Literature Cited}

Adams, J.E., D. Kirkham, and D.R. Nelson. 1957. A portable infiltrometer and physical measurements of soil in place. Soil Sci. Soc. Amer. Proc. 21:473-477.

Bertrand, A.R., and J.F. Parr. 1961. Design and operation of the Purdue sprinkling infiltrometer. Purdue Univ. Res. Bull. No. 723, Lafayette, Ind.

Blackburn, W.H., R.O. Meewig, and C.M. Skau. 1974. A mobile infiltrometer for use on rangeland J. Range Manage. 27:322-323.

Bubenzer, G.D. 1979. Inventory of rainfall simulators. Proc. Rainfall Simulator Workshop. Tucson, Ariz. p. 120-130.

Dortignac, D.J. 1951. Design and operation of Rocky Mountain infiltrometer. Rocky Mountain Forest and Range Exp. Sta. Paper 5.

Elkins, N.Z. 1983. Potential mediation by desert subterranean termites in infiltration, runoff and erosion soil loss on a desert watershed. Diss. New Mexico State Univ., Las Cruces.

Foster, G.R., F.P. Eppert, and L.D. Meyer. 1979. A programmable rainfall simulator for field plots. Proc. Rainfall Simulator Workshop. Tucson, Ariz. p. 45-59.

Laws, J.O. 1941. Management of the fall velocity of waterdrops and raindrops. Trans. Amer. Geophy. Union. 22:709-721.

Laws, J.O., and D.A. Parsons. 1943. Relation of raindrop size to intensity. Trans. Amer. Geophy. Union 24:452-460.

Malekuti, A., and G.F. Gifford. 1978. Natural vegetation as a source of diffuse salt within the Colorado River Basin. Water Resour. Bull. 14:195-205.

McQueen, J.S. 1963. Development of a hand-portable rainfall-simulator infiltrometer. US Geol. Survey Circ. 482.

Munn, J.R., and G.L. Huntington. 1976. A portable rainfall simulator for erodibility and infiltration measurements on rugged terrain. Soil Sci. Soc. Amer. Proc. 40:622-624.

Mutchler, C.K., and L.F. Hermsmeier. 1965. A review of rainfall simulators. Trans. Amer. Soc. Agr. Engr. 8:67-68.

Selby, M.J. 1970. Design of a hand-portable infiltrometer, with trial results from Otutira catchment. J. Hydrol. 9:117-132. 